ECC-NE-10257

DE92 018042

\title{
Broad-Application Test Reactor
}

\author{
Chester G. Motloch
}

Published May 1992

\section{Idaho National Engineering Laboratory \\ EG\&G Inaho, Inc. \\ Idaho Falls, Idaho 83415}

Prepared for the

U.S. Department of Energy

Assistant Secretary for Nuclear Energy

Under DOE Idaho Field Office

Contract DE-AC07-76ID01570

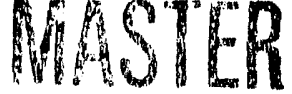

BISTRIBUTION OF TIIS DOCURIENT IS UNLIMITES 


\begin{abstract}
This report is about a new, safe, and operationally efficient DOE reactor for nuclear research and testing proposed for the early to mid-21st Century. Dubbed the Broad-Application Test Reactor (BATR), the proposed facility incorporates a multiple-application, multiple-mission design to support DOE programs such as naval reactors and space priwer and propulsion, as well as research in medical, science, isotope, and elecironics arenas. DO $\mathrm{rec}$ h reactors are aging, and implementing major replacement projects requires long lead times. Primary design drivers include safety, low risk, minimum operation cost, mission llexibility, waste minimization, and long life. Scientists and engineers at the Idaho National Engine, ing Laboratory are evaluating possible fucl forms, structural matcriats, reactor geometries, coolants, and moderators.
\end{abstract}




\section{EXECUTIVE SUMMARY}

The need to test fuels and materials and to produce isotopes for medical and other applications will continue. In addition, new needs are arising to support advanced research such as space nuclear power and propulsion. We must continually modernize and push science and technology forward to maintain our national preeminence and international competitiveness in nuclear research and testing, fuels and matcrial research, and science and engineering education and training.

For the United States to have the test facilities to support nuclear research and testing in the early to mid-21st Century, we need to start planning now. To this end, the Idaho National Engineering Laboratory (INEL) has begun preliminary planning and preconreptual design of a new-generation test reactor. We envision this reactor as satisfying a wide range of user needs and fullilling a broad spectrum of applications; hence, the name Broad-Application Test Reactor (BATR).

Reasons for considering BATR now are (1) comparable-mission DOE reactors are aging and may become technologically obsolete, (2) the Advanced Test Reactor (ATR) will eventually be shut down, with no replacement currently planned, and (3) because of today's long lead times in our stringent regulatory and compliance-driven environment, long-range planning is critical for major new projects.

Potential BATR users are Naval Reactors, Space Power and Propulsion (NE), Department of Defense (DOD), National Aeron?utics and Space Administration (NASA), plus medical, science, and electronics communities. 


\section{CONTENTS}

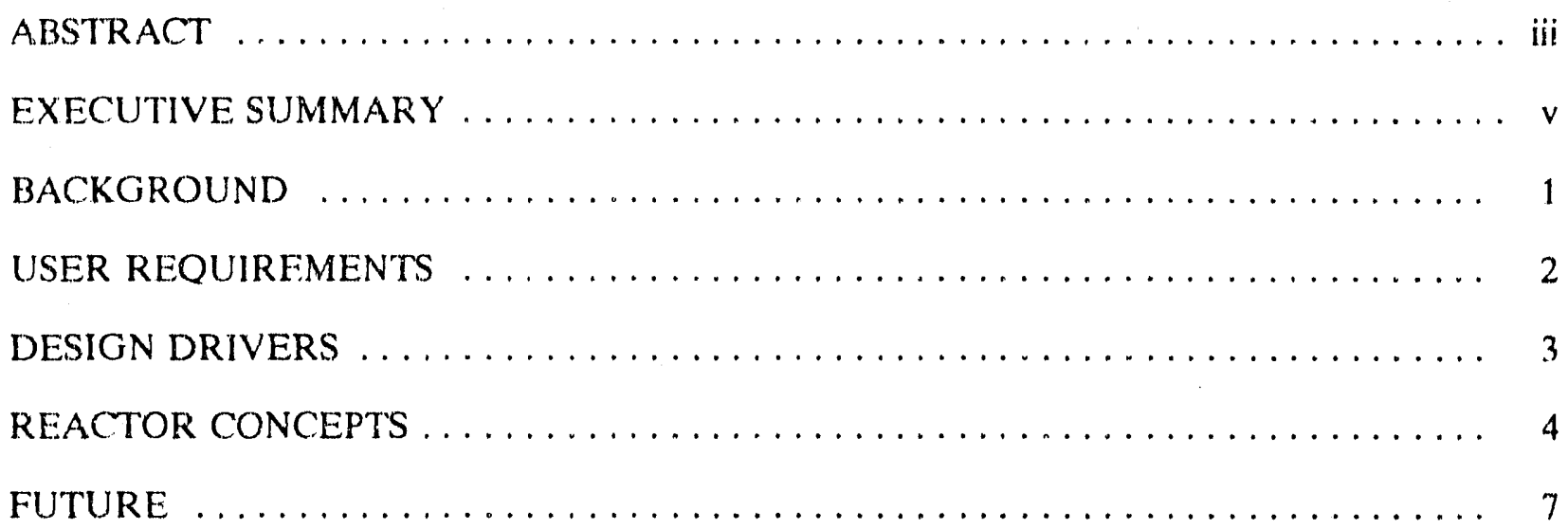




\section{Broad-Application Test Reactor}

\section{BACKGROUND}

A gap is developing in U.S. nuclear research capabilities. Our surveys show that we have started no construction in this country of a new research or test reactor over $5 \mathrm{MW}$ in more than 20 years; and in all of the Western world, only onc has been commissioned. In contrast, the East, Mideast, and third-world countries have started more than 30 new reactors.

Only four comparable Department of Encrgy (DOE) test reactors with missions similar to BATR's currently exist in this country. They are the Advanced Test Reactor (ATR) at the Idaho National Engineering Laboratory (INEL), the Fast Flux Test Facility (FFTF) at Hanford, the High Flux Bearn Reactor (HFBR) at Brookhaven, and the High Flux Isotope Reactor (HFIR) at Oak Ridge. HFBR and HFIR are scheduled for shuldown around the year 2000; ATR first went eritical in 1967; and the future of FFTF is unecrtain. Thus, unless we strengthen our current efforts, this country could be left with seriously limited nuclear rescarch and testing capabilities shortly after the turn of the century.

Fortunately, for several years Congress has funded scientists at Oak Ridge with help from the INEL to begin design work on a new research reactor, the Advanced Ncutron Source (ANS). The focus of ANS, however, is neutron scaftering research, which leaves the much broader and nearer-term engineering applications unaddressed. An ORNL report (ORNL/CONF-901276) states that "it is generally agreed that the ANS cannot be the sole neutron source upon which a national irradiation-effects program is based." The report lurther states that ". . if the United States does not take some action ... then it must be assumed that our national strategy is to use overseas facilities. . ." Clearly, it is undesirable that our country's scientific and defense nuclear research and testing depend on foreign facilities.

Hence, there is a need for a second reactor that will complement the capabilities of the ANS and cover the remaining critical research and materials testing demands and isotope production requirements. 


\section{USER REQUIREMENTS}

Initial planning and studies for BATR were begun in late 1990 employing a team of senior INEL engineers and scientists in an array of disciplines with emphasis on safely and user needs. An carly activity of this process was icientilying and ranking the following user needs:

- Fucls and materials irradiation testing

- Isolope production

- Space nuclear power and propulsion testing

- Silicon doping for the electronics industry.

Trends show that the Navy will continue to need fuels and materials testing. NASA's Space Exploration Initiative will require new facilities for space nuclear power and propulsion testing. National defense will need llexible, cost effective means of generating modest quantities of ${ }^{3} \mathrm{H}$. NASA will continue to need ${ }^{238} \mathrm{Pu}$ for radioisotopic thermoelectric generators for space power supplies. The medical industry will continue to demand high value isotopes such as ${ }^{99} \mathrm{Mo}$ and ${ }^{60} \mathrm{Co}$, and the electronics industry will continue to need silicon doping. The extent of these needs continues to be assessed and will change with time. A reactor is needed that provides mission flexibility at reduced operational cost and with enhanced safety leatures. Clearly, to satisfy these diverse mission requirements within a single facility will require an innovative approach to both reactor design and operation.

The design goal for BATR must stress multimission applications while providing preeminent nuclear testing capabilities. The table below lists the basic BATR design features needed to achieve these goals. A high neutron flux $\left(>10^{15}\right.$ neutrons $\left./ \mathrm{cm}^{2} / \mathrm{sec}\right)$ and a large test volume $(>50 \mathrm{~L})$ are needed tor many applications, including irradiation testing, medical isotopes, isotopes for space power, positron facility, and materials research. To satisfy this variety of applications, neutron fluxes ranging from the cold to fast spectrum are needed. For example, a cold spectrum is needed for materials and magnetism; a thermal spectrum is needed for irradiation tests, isotope production, transmutation doping, and positron production; an epithermal spectrum is needed for medical and isotope production; and a fast spectrum is needed for irradiation tests, fusion, space nuclear fuels testing, and isotope production. This further necessitates some special reactor design features, including a flexible, reconformable core geometry, loops, neutron beams, test holes, rabbits, and other devices to allow insertion and removal of test articles during reactor operation.

BATR Design Features

$\begin{array}{llll}\begin{array}{l}\text { Neutron } \\ \text { Flux } \\ \left(\mathrm{cm}^{-2} \mathrm{~s}^{-1}\right)\end{array} & \text { Test } & \text { Neutron } & \text { Special } \\ & \text { Volume } & \text { Energy } & \text { Features } \\ >10^{15} & (\mathrm{~L}) & \text { Cold } & \text { Reconformable } \\ & 50 & \text { Thermal } & \text { Loops } \\ & & \text { Epithermal } & \text { Beams } \\ & & \text { Fast } & \text { Rabbit }\end{array}$




\section{DESIGN DRIVERS}

Through the evolution of several carly concepts, we have identified the following high-priority design drivers:

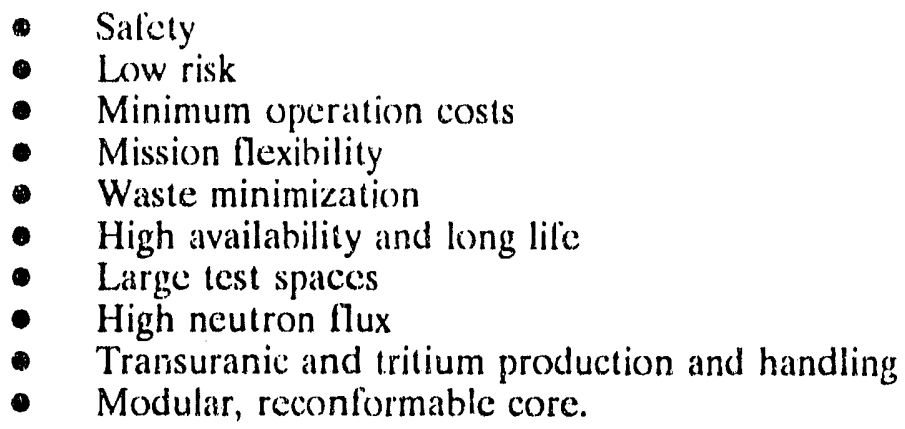

In addition, the list of medium- and lower-priority design drivers is extensive, all of which have to be balanced against llexibility without undue compromise of performance. This combination of capabilities does not exist in any current or proposed commercial or university facility. A set of top-level goals has been established:

- A llexible ncutron flux facility for future generation experimental testing and production

- A reactor design that emphasizes

- Environment, safety, and health

- Performance optimization

- Risk and cost minimization

- Broad and changing user needs.

Recognizing the undisputed primary importance of safety, we have adopted a philosophy based on a technical approach called probabilistic risk assessment, which will be integral to early design. This will help ensure mecting U.S. Nuclear Regulatory Commission and International Atomic Energy Agency safety goals. Environmental concerns are also paramount. In fact, to succeed on a reasonable schedule, the environmental impact statement process must begin soon. 


\section{REACTOR CONCEPTS}

Because of the breadth of missions under consideration, operational flexibility is high on the list of design drivers. With this in mind, a number of concepts are being evaluated by INEL scientists and engineers. Initial comparisons have been completed, and tradeoff studies have been performed assessing the advantages and disadvantages of various fucl forms, structural materials, reactor geometries, coolants, and moderators. The combinations considered included the following:

- Conventional aluminum or zirconium fuel plates in combinations with

light- or heavy-water coolant/moderator

- Particle bed

- Rotating rings

- Cermet-fucled, liciuid metal-cooled

- Accelerator, spallation neutron source

- TRIGA

- Pebble bed

- Molten chloride.

Safely is the major criteria in the evaluation process. Because of the tremendous power densities required ( $>1 \mathrm{MW} / \mathrm{L}$ ), coolability of the core is an overriding concern. At these power densities, the core cannot be cooled passively; and forced convection will be a required feature of the safety systems.

Out of this evaluation, two main contenders have surfaced, both of which employ highly enriched piate fuel and are light-water cooled and heavy-water reflected. Both also have target positions, loops, test holes, and rabbits, and have similar cooling system schemes. The first is a modular-hexagonal core, the second a multiple-annular distributed core. One important distinguishing feature between the two is that the first is tightly coupled neutronically, whereas the second is more loosely coupled. Our preliminary studies indicate that both concepts show potential for an excellent match with safety requiremerts and facility user needs. Detailed discussion of this study is found in Salety Requirements, Facility User Needs, and Reactor Concepts for a New Broad Application Test Reactor, EG\&G Idaho, Inc., NRRT-N-91-036, October 1991.

The following two figures are computer-generated illustrations of an example vessel and piping layout and an example core for the two different concepts. The first figure shows some key features of the reactor vessel and piping layout for the modular-hexagonal concept. Three cold legs supply light water coolant to a common lower plenum where it is mixed and flows upward through each fuel assembly. Upon leaving the core, the coolant collects in the upper plenum and flows to individual cooling loops through the three hot legs. As in the multiple-annular distributed concept, each of the seven test loops are independently cooled. Also, the temperature of the heavy-water reflector is maintained by a separate reflector cooling system. Twelve rabbit tubes allow insertion and removal of test samples during reactor operation, and the three beam tubes facilitate neutron scattering research. The six control drives regulate the position of the scram blades.

The second ligure depiets an example core conliguration, with mixed fuel for the multiple-annular distribuled concept. In this example, the core consists of seven loosely coupled fuel assemblics positioned in a heavy-water rellector tank. Each fuel assembly is contained in a separate pressure boundary cooled by light water. And, each of the seven test loops within the fuel assemblies is individually cooled. The ATR-type arcuate fuel and the concentric fuel shown in the first figure are two of several fuel forms possible in these concepts. With this ability to utilize a variety of fucl forms simultancously, various concurrent missions are possible, such as tritium production and nuclear fueis and materials experiments. 


\section{LAYOUT OF THE MODULAR HEXAGONAL BATR CONCEPT}

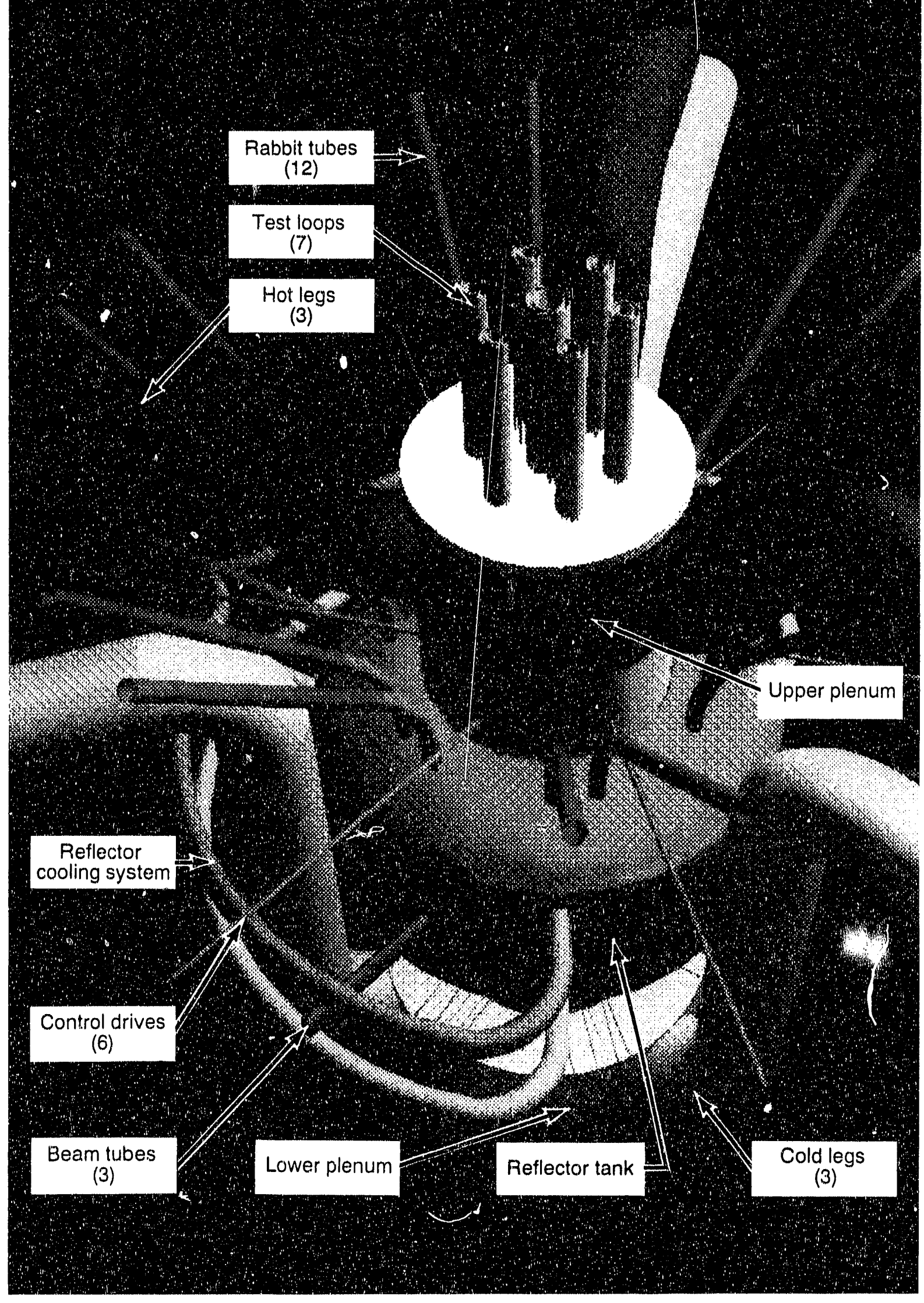




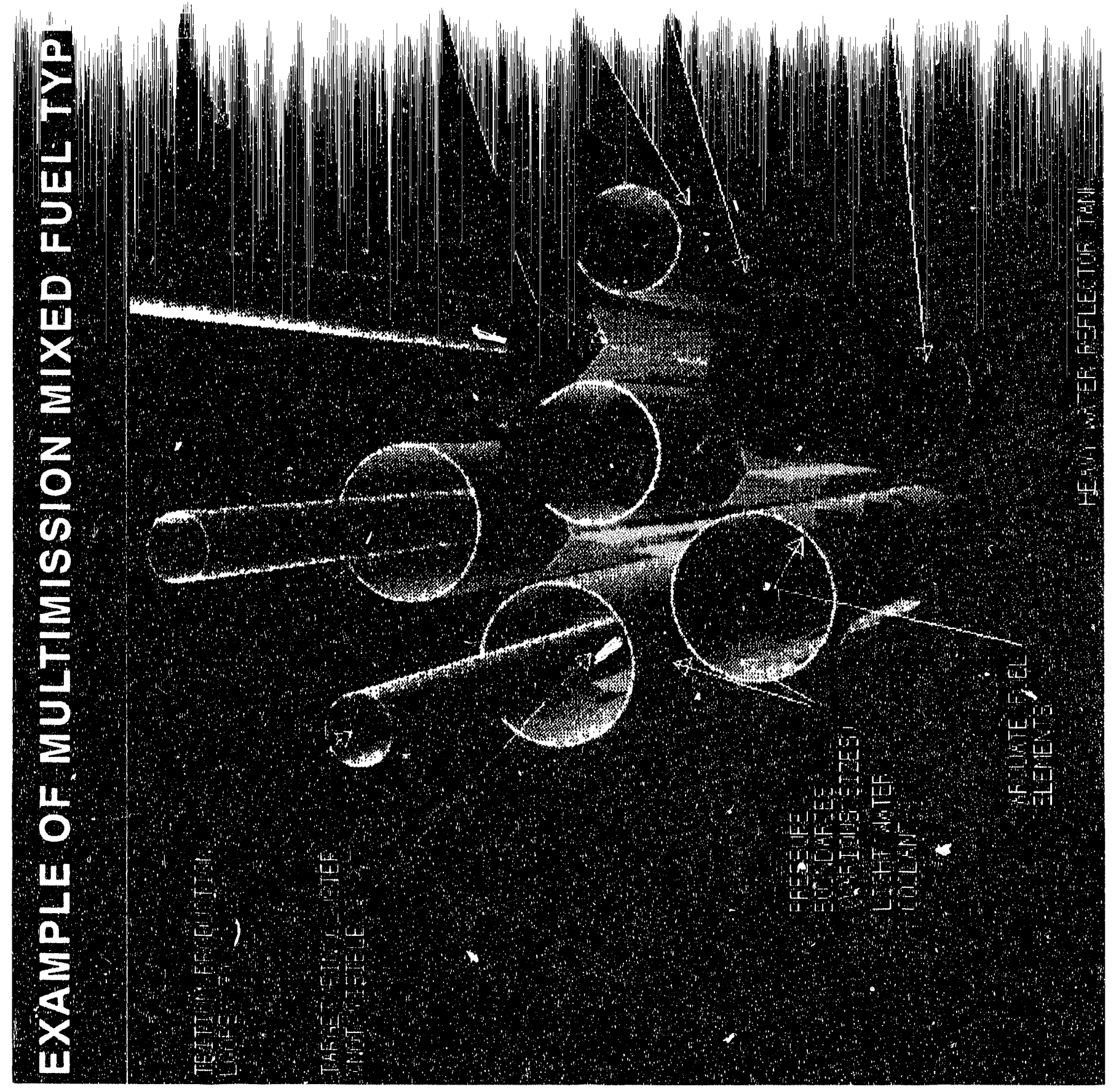




\section{FUTURE}

Rather than speculate about our nation's nuclear research and testing needs 15 years into the luture, part of BATR planning is to meet with potential customers to obtain requirements and needs. One-on-one mectings are planned between DOE-ID and directors and deputy assistant secretaries with DOE-NE Civilian Reactor Development, Space and Delense Power Systems, and Naval Reactors to seck endorsements for the BATR concept. Further, an advocacy base needs to be established with other potential customers including the Air Force, NASA, and various university and commercial interests.

These initial meetings with DOE-NE are planned for the third quarter of FY-1992, with more formal presentations to follow as requested. A more quantitative definition of the need for BATR should be available by mid-summer.

Continued progress in assessing promising concepts will require funding to advance to the next design stage. The logical source of this funding is DOE-NE. One or more base-load customers is needed who can be flexible and accommodate sharing the reactor with other missions. Cost sharing may be an effective solution to many user needs. However, long project schedules create uncertainty and lack of commitme $-t$; and the nation and DOE are under increasing budgetary pressure.

Some fundamental questions must be answered. Can a single reactor effectively support. multiple missions? Should the BATR design be evolutionary or revolutionary? Should BATR be based on best available technoiogy or should it push for advanced innovative approaches? Can BATR be a fast-track demonstration project of 8 years or less? (Under the current DOE Order 4700.1, Project Managements System, major construction projects typically require 15 or more years, and a new draft of 4700.1 extends this time even further.) Can the size of the operating staff and commensurate operating costs be significantly reduced? Is cost-sharing a practical approach?

The BATR project needs an integrated, systems approach that addresses today's issues, including safety, risk, operational cost, waste minimization, and flexibility. To meet the projected nuclear engineering rescarch, testing, and educational needs of our country in the 21 st Century, we must continue our Broad-Application Test Reactor planning. As the nation's largest enclave of research and test reactors, it is the responsibility of the INEL to foster this effort.

For additional information, contact Dr. John Ryskamp (208-525-5516) or Mr. Chet Motloch (208-526-025.3) at the INEL. 

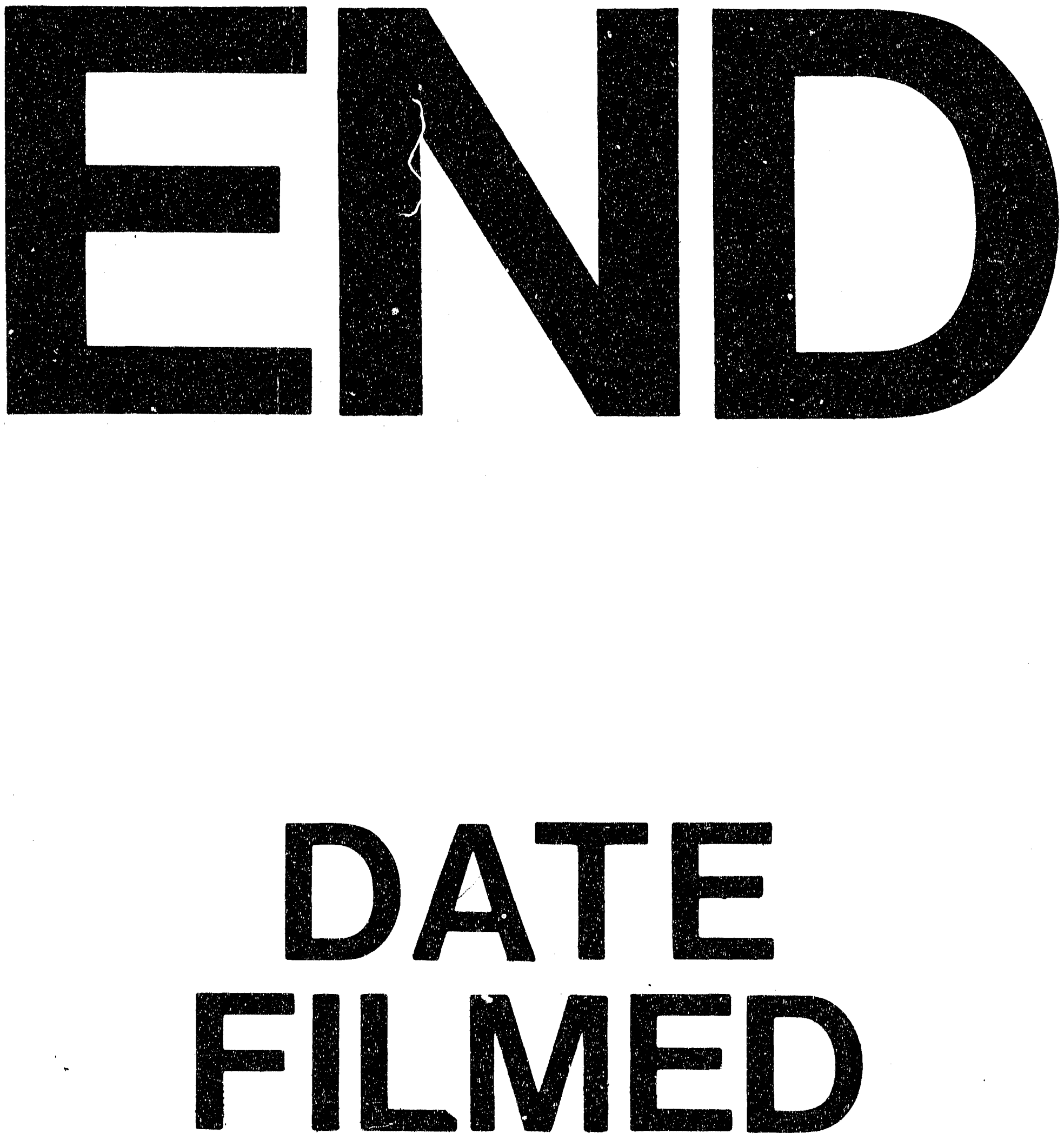

$\exists$

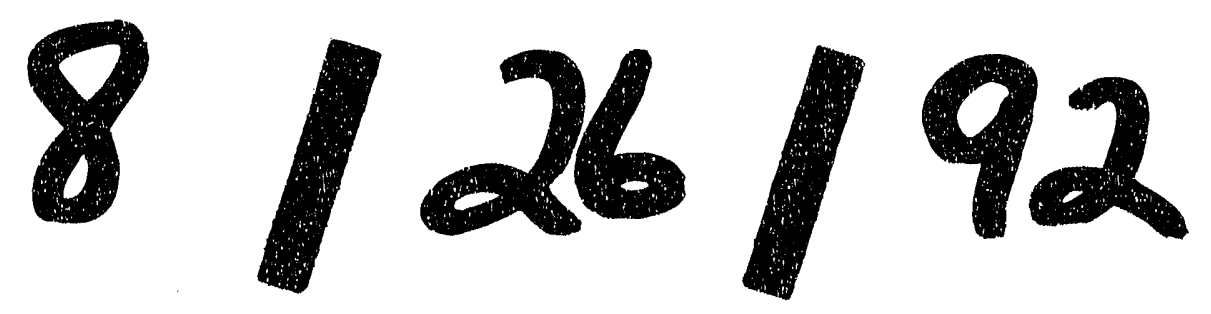

